DOI: 10.12731/2227-930X-2016-1-57-80

\title{
CONCERNING CHAIN GROWTH SPECIFIC REACTION RATE AS A PART OF THE PROCESS OF METHYL METHACRYLATE MASS RADICAL POLYMERIZATION
}

\section{Sultanova A.A., Yanborisov V.M., Kolesov S.V.}

It is the chain growth specific reaction rate that was determined for the process of methyl methacrylate mass radical polymerization within the temperature range of 40-900 C in quasi-steady approximation by means of Monte Carlo method. The theoretical model of radical polymerization was developed taking the gel effect into account. Computer software was developed that enables to imitate radical polymerization process taking gel effect into account within the minimum run time. The programme was tested on asymptotic examples as well as was applied for methyl methacrylate mass radical polymerization. The programme makes it possible to calculate monomer conversion, molecular mass variation, molecular-mass distribution, etc.

Keywords: chain growth specific reaction rate; gel effect; methyl methacrylate; Monte Carlo method; mass radical polymerization.

\section{Introduction}

Radical polymerization process has been of great interest not only due to its significant practical value and the need to improve ways to control this complicated process, but also due to the rapid research development of the process's promising variants, namely, 'pseudolive', complex-radical, as well as radical-coordination polymerization variant. That, along with the improvement of experimental methods of research, contributes to developing methods of mathematical simulation of polymerization processes. The use of modern computing techno- 
logies ensures effective forecasting of kinetic regularities of polymerization, molecular structure and molecular mass characteristics of the products, as well as forecasting of practically relevant physical and chemical properties of polymers [1-4]. The application of computational methods is especially significant for the analysis of complex mechanisms of radical polymerization. The application of methods of mathematical simulation to the research of other types of catalytic polymerization [2-3], being unconditionally positive, proves this approach in the case of dealing with radical processes to be promising. However, it is even simulation of the standard mass radical polymerization of typical monomers that is not a trivial task. At the end of the 40 s it was found that mass radical polymerization of methyl methacrylate (MMA) is accompanied by the gel effect [5], that is, a sharp increase in both the polymerization rate and molecular mass (MM) at considerably high conversions. Thus, while the MMA polymerization is taking place, acceleration can be observed at the conversion rate of $0.15-0.2$ [6] or 0.6 [7]. Therefore, the gel effects should be taken into account while studying kinetics and determining the polymerization rate.

One of the models of taking the gel effect into account in the case of styrene polymerization is thought to be the Hui-Hamielec model. The model is based on empirical dependence of the chain termination reaction rate $\left(k_{\mathrm{t}}\right)$ on monomer conversion $(x): k_{t}=k_{t 0} \cdot \exp (-E / R T) \cdot \operatorname{ex}-$ $\mathrm{p}\left(-2\left(A_{1} x+A_{2} x^{2}+A_{3} x^{3}\right)\right)$, where $k_{t 0} \cdot \exp (-E / R T)$ is the chain termination reaction rate without taking the gel effect into account [8].

For the purposes of numerical simulation of MMA polymerization and quantitative correlation between the estimated and observed dependences one should know the exact real chain growth reaction rate $\left(k_{p}\right)$ at various temperatures.

There are quite a lot of methods available for determining the value of $k_{p}$. In [9], chain growth reaction rate was found by interpreting the experimental data obtained by various researchers (Table 1). Howev- 
$\mathrm{er}$, in general, the researchers determine the chain growth reaction rate value by interpreting their own experimental data only.

Table 1.

Chain growth reaction rate in the Arrhenius equation form $k_{p}=k_{p 0} \cdot \exp (-E / R T)$

\begin{tabular}{|c|c|c|c|}
\hline $\boldsymbol{k}_{\boldsymbol{p} \mathbf{0}} \mathbf{1 0} \mathbf{5}, \mathbf{L} /(\mathbf{m o l} \cdot \mathbf{s e c})$ & $\mathbf{E} / \mathbf{R}, \mathbf{K}$ & Determination method & Ref. \\
\hline 6.6 & 2367 & $\begin{array}{c}\text { Interpretation of the experimental } \\
\text { data }\end{array}$ & {$[9]$} \\
\hline 4.92 & 2198 & SIP & {$[10]$} \\
\hline 4.9 & 2190 & SIP & {$[11]$} \\
\hline 25 & $2766 \pm 300$ & Electron spin resonance & {$[12]$} \\
\hline
\end{tabular}

Until recently the main method of determining the chain growth reaction rate was thought to be the 'rotating sector' method [13]. The article [14] describes surface initiated polymerization (SIP). The SIP method is similar to the 'rotating sector' method as the monomer and initiator solution flows through an unlit tubular reactor past regularly placed splits that permit light through. The chain growth reaction rate determined using the SIP method can be found in [10-11] (Table 1). The value obtained was applied in [15-16] to describe mass radical polymerization of methyl methacrylate (MMA) in theory.

The 'spin trapping' method has become quite widespread for the purposes of obtaining data on the chain growth reaction rate. The method is based on the reaction of the non-paramagnetic molecule (trap) with a short-lived radical specifically placed into the medium under study, the result being formation of a stable radical that is characterized by having specific electron paramagnetic resonance. The use of spin trapping enables to identify short-lived radical products [17]. The chain growth reaction rate determined using the above-mentioned method can be found in [12] (Table 1).

The most reliable method of determining the chain growth reaction rate is thought to be pulsed-laser polymerization (PLP) [18]. The method consists in irradiating the vessel containing the monomer 
with high power pulsed laser radiation, which results in generating a considerable amount of radicals that destroy virtually all previously formed ones. The new radicals that survived initiate polymerization of new macroradicals that grow until the next pulse [19]. The value of $k_{\mathrm{p}}$, relevant for MMA polymerization, was published in [19].

The study is aimed at determining the chain growth reaction rate in quasi-steady approximation as well as at simulating MMA mass polymerization using the Monte Carlo (MC) method taking the gel effect into account.

\section{Model core}

The following reactions were considered while simulating MMS polymerization:

substance initiation

chain growth

chain transfer to monomer

recombination

disproportioning

$$
\begin{aligned}
& I \stackrel{k_{d}}{\longrightarrow} 2 R_{0}^{\circ} \\
& R_{p}^{\cdot}+M \stackrel{k_{p}}{\longrightarrow} R_{p+1}^{\cdot} \\
& R_{p}^{\bullet}+M \stackrel{k_{m}}{\longrightarrow} R_{1}^{\bullet}+P_{p} \\
& R_{p}^{\cdot}+R_{j}^{\cdot} \stackrel{k_{\text {com }}}{\longrightarrow} P_{p+j} \\
& R_{p}^{\cdot}+R_{j}^{\cdot} \stackrel{k_{\text {disp }}}{\longrightarrow} P_{p}+P_{j},
\end{aligned}
$$

where $I, M, R$ ', $P$ are initiator, monomer, growing radical, 'dead' macromolecule; whereas index is the polymerization degree, $k_{d^{\prime}} k_{p^{\prime}}$, $k_{m}, k_{\text {disp }}, k_{\text {com }}$ are rates of substance initiation reaction, chain growth, chain transfer to monomer, disproportioning and macroradicals recombination.

A possible thermal initiation reaction was thought to be irrelevant due to the fact that PMMA synthesis simulation was carried out at relatively low temperatures. Also, chain transfer to initiator and polymer reactions were thought to be irrelevant due to their improbable nature.

The MMA polymerization process under study correlates to a system of differential equations:

$$
\frac{d[I]}{d t}=-k_{d} \cdot[I]
$$




$$
\begin{gathered}
\frac{d[M]}{d t}=-\left[R^{\bullet}\right] \cdot[M] \cdot\left(k_{p}+k_{m}\right) \\
\frac{d\left[R^{\bullet}\right]}{d t}=2 \cdot f \cdot k_{d} \cdot[I]-\left[R^{\bullet}\right]^{2} \cdot\left(k_{\text {disp }}+k_{\text {com }}\right),
\end{gathered}
$$

where $f$ is substance initiation reaction efficiency.

The simulation of MMA radical polymerization by azobisisobutyronitrile (AIBN) and benzoyl peroxide (PBO) involved reported values of reaction rates (Table 2 ).

Table 2 .

\begin{tabular}{|c|c|c|}
\hline Parameters & Values & Ref. \\
\hline$k_{t 0}=k_{\text {rec }}+k_{\text {disp }}$ & $9.8 \cdot 10^{7} \cdot \exp (-353 / T), \mathrm{L} /(\mathrm{mol} \cdot \mathrm{sec})$ & {$[10]$} \\
\hline$k_{t}$ & $k_{t 0} \cdot \exp \left(-2\left(A_{1} x+A_{2} x^{2}+A_{3} x^{3}\right)\right)$ & [8] \\
\hline$n=k_{\text {rec }} / k_{\text {disp }}$ & $3.956 \cdot 10^{-4} \cdot \exp (-2065 / T)$ & [20] \\
\hline$k_{\text {disp }}$ & $k_{t} \cdot n /(n+1), \mathrm{L} /(\mathrm{mol} \cdot \mathrm{sec})$ & \multirow{2}{*}{ [21] } \\
\hline$k_{c o m}$ & $k_{t} /(n+1), \mathrm{L} /(\mathrm{mol} \cdot \mathrm{sec})$ & \\
\hline$f(\mathrm{AIBN})$ & 0.5 & \multirow{2}{*}[22]{} \\
\hline$k_{d}(\mathrm{AIBN})$ & $1.053 \cdot 10^{15} \cdot \exp (-15440 / T), \mathrm{c}^{-1}$ & \\
\hline$f(\mathrm{PBO})$ & 1 & \multirow{2}{*}{ [9] } \\
\hline$k_{d}(\mathrm{PBO})$ & $1.18 \cdot 10^{14} \cdot \exp (-15097 / T), \mathrm{c}^{-1}$ & \\
\hline
\end{tabular}

Parameters values for simulation of MMA mass radical polymerization

\section{Experimental part}

MMA (by Fluka) was double distilled under vacuum. For the purposes of polymerization, the MMA fraction with $\mathrm{T}_{\text {boil }}=39^{\circ} \mathrm{C}$ at $p=100$ $\mathrm{mmHG}, \mathrm{n}_{\mathrm{D}}{ }^{20}=1.4130, \mathrm{~d}_{4}{ }^{20}=0.936 \mathrm{~g} / \mathrm{ml}$ was used. The clarity degree of monomers was controlled using the method of MNR ${ }^{1} \mathrm{H}$ - and ${ }^{13} \mathrm{C}$.

The AIBN and PBO initiators were double recrystallized from methanol and then were dried under vacuum at room temperature until the fixed mass value was reached.

Conversion dependences were obtained using the dilatometric method [6]. 
For the MMA mass polymerization the reaction mixture was poured into an ampule, then the solution was degassed by a triple cycle of freezing - defrosting till the residual pressure of $1.3 \mathrm{~Pa}$ was detected. The ampule was then sealed and placed in a thermostat (capable of maintaining $\pm 0.1^{\circ} \mathrm{C}$ temperature accuracy) and kept until the required conversion degree was obtained, the one calculated using the formula:

$$
x=D V /\left(V_{0} \times k\right) \text {, }
$$

where $V_{0}$ - monomer initial volume, $\mathrm{D} V$ - its variation, $k=\left(V_{n}-V_{n}\right) /$ $V_{M}$ - contraction coefficient, $V_{\mu}$ и $V_{n}$ - monomer and polymer specific volumes [23]. Once polymerization had taken place, the ampules were cooled and opened. The polymeric product obtained was dissolved in acetone and then deposited with 10-15-fold excess of ethanol. The polymer was cleared of the rest of the initiator using triple redeposition. The polymer was then dried under vacuum $\left(T=40^{\circ} \mathrm{C}\right)$ until the fixed mass value was reached.

Polymer molecular-mass distribution (MMD) and average molecular mass (MM) were determined by gel-permeation chromatography. The analyses were performed using a Waters GPC 2000 System liquid chromatograph (eluent: chloroform, flow speed: $0.5 \mathrm{ml} / \mathrm{min}$ ). The pin system was calibrated according to polystyrene standards $\bar{M}_{\mathrm{w}} / \bar{M}_{\mathrm{n}} \leq 1.2$.

\section{Determination of chain growth reaction rate in quasi-steady approximation}

From the historical point of view, it is the method based on quasi-steady approximation that is the first to be used to determine the chain growth reaction rate. It was suggested that the chain termination rate fails to depend on conversion: $k_{t}=k_{t 0}=$ const. Using $d\left[R^{*}\right] / d t=0$ approximation, the quasi-steady macroradical concentration was calculated:

$$
\left[R^{\bullet}\right] \approx \sqrt{\frac{2 \cdot f \cdot k_{d}}{k_{t 0}}[I]_{0}}
$$


as well as chain growth reaction rate was determined taking the initial polymerization rate into account:

$$
k_{p} \approx \frac{V_{\text {Hau }}}{[M]_{0} \cdot\left[R^{\bullet}\right]}
$$

where $[M]_{0}=9.39 \mathrm{~mol} / \mathrm{L}-$ initial monomer concentration.

The initial polymerization rate was determined by approximation of experimental conversion dependencies of the study as well as the data published in [24-29] using the least-square method on the initial section of the curve $x \leq 0.15$ (Table 3 ). The initial section of conversion curves is approximated by linear dependence with a high correlation coefficient $r \geq 0.9964$ (Pic. 1).

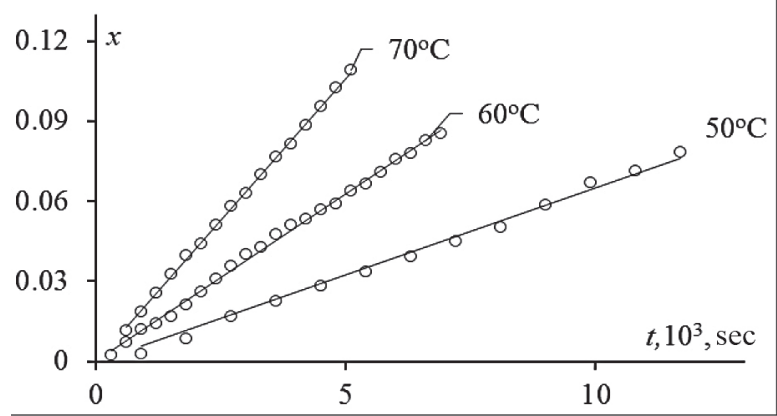

Pic. 1. Typical initial section of MMA conversion, $[\mathrm{AIBN}]_{0}=1 \mathrm{mmol} / \mathrm{L}$

Table 3 .

Kinetic parameters of MMA mass polymerization

\begin{tabular}{|c|c|c|c|c|c|c|c|c|}
\hline$T,{ }^{\circ} \mathbf{C}$ & Initiator & {$[I]_{0}, \mathrm{mmol} / \mathrm{L}$} & Ref. & \multicolumn{3}{|c|}{$\begin{array}{c}V_{0} \cdot 10^{5}, \mathrm{~mol} / \\
(\mathrm{L} \cdot \mathrm{sec})\end{array}$} & $\begin{array}{c}{\left[R^{\top}\right] \cdot 10^{8},} \\
\mathrm{~mol} / \mathrm{L}\end{array}$ & $\begin{array}{c}k_{p}, \mathbf{L} / \\
(\mathbf{m o l} \cdot \mathbf{s e c})\end{array}$ \\
\hline \multirow{6}{*}{45} & AIBN & 6.25 & \multirow{6}{*}{ [24] } & 5.90 & \pm & 0.20 & 1.3 & 480 \\
\hline & AIBN & 12.5 & & 10.0 & \pm & 1.0 & 1.9 & 560 \\
\hline & AIBN & 25 & & 12.5 & \pm & 8.7 & 2.6 & 509 \\
\hline & AIBN & 50 & & 16.7 & \pm & 1.4 & 3.7 & 480 \\
\hline & AIBN & 100 & & 22.0 & \pm & 5.0 & 5.2 & 427 \\
\hline & AIBN & 200 & & 29.52 & \pm & 0.15 & 7.4 & $\begin{array}{c}425 \\
480 \pm 51 * *\end{array}$ \\
\hline
\end{tabular}


End of Table 1.

\begin{tabular}{|c|c|c|c|c|c|c|c|c|}
\hline \multirow{8}{*}{50} & AIBN & 1 & $*$ & 4.11 & \pm & 0.02 & 0.8 & 580 \\
\hline & AIBN & 3 & $*$ & 7.3 & \pm & 0.08 & 1.3 & 595 \\
\hline & AIBN & 15.48 & [25] & 14.2 & \pm & 3.7 & 3 & 485 \\
\hline & AIBN & 15.5 & [25] & 15.1 & \pm & 2.9 & 4.3 & 354 \\
\hline & AIBN & 25.8 & [26] & 18.8 & \pm & 3.6 & 3 & 674 \\
\hline & AIBN & 25.8 & [26] & 18.19 & \pm & 0.93 & 3.8 & 506 \\
\hline & PBO & 43 & [27] & 15.73 & \pm & 0.31 & 4 & 421 \\
\hline & & & & & & & & $516 \pm 111 * *$ \\
\hline \multirow{10}{*}{60} & AIBN & 1 & $*$ & 11.38 & \pm & 0.04 & 1.5 & 797 \\
\hline & AIBN & 3 & $*$ & 19.57 & \pm & 0.19 & 2.9 & 708 \\
\hline & AIBN & 5.6 & [28] & 22.5 & \pm & 1.0 & 3.6 & 688 \\
\hline & AIBN & 11.2 & [28] & 30.5 & \pm & 0.66 & 5.1 & 617 \\
\hline & AIBN & 28 & [28] & 46.38 & \pm & 0.41 & 8 & 659 \\
\hline & AIBN & 56 & [28] & 63.04 & \pm & 0.99 & 11.4 & 590 \\
\hline & AIBN & 100 & [29] & 83.7 & \pm & 1.8 & 15.2 & 586 \\
\hline & PBO & 1 & $*$ & 8.610 & \pm & 0.01 & 1.2 & 761 \\
\hline & PBO & 21.4 & [27] & 26.86 & \pm & 0.29 & 5.6 & 513 \\
\hline & & & & & & & & $658 \pm 78 * *$ \\
\hline \multirow{8}{*}{70} & AIBN & 1 & $*$ & 20.43 & \pm & 0.08 & 2.3 & 740 \\
\hline & AIBN & 3 & $*$ & 40.4 & \pm & 1.2 & 5.1 & 844 \\
\hline & AIBN & 15.48 & {$[25]$} & 94.9 & \pm & 1.8 & 11.6 & 874 \\
\hline & AIBN & 15.5 & [26] & 86 & \pm & 37 & 11.6 & 794 \\
\hline & AIBN & 25.8 & [25] & 110 & \pm & 16 & 15 & 788 \\
\hline & AIBN & 25.8 & [26] & 119.8 & \pm & 7.1 & 14.9 & 854 \\
\hline & PBO & 1 & $*$ & 17.81 & \pm & 0.07 & 2.3 & 827 \\
\hline & & & & & & & & $817 \pm 46^{* *}$ \\
\hline \multirow{3}{*}{80} & AIBN & 3 & $*$ & 85.89 & \pm & 0.17 & 9.5 & 964 \\
\hline & PBO & 1 & $*$ & 37.81 & \pm & 0.17 & 4.2 & 955 \\
\hline & & & & & & & & $959 \pm 6 * *$ \\
\hline \multirow{4}{*}{90} & AIBN & 15.5 & [26] & 445 & \pm & 47 & 38.9 & 1220 \\
\hline & AIBN & 15.48 & [25] & 391 & \pm & 37 & 38.9 & 1071 \\
\hline & AIBN & 25.8 & [25] & 460 & \pm & 181 & 50.1 & 978 \\
\hline & & & & & & & & $1146 \pm 122 * *$ \\
\hline
\end{tabular}

* - according to the study, ** - average values

$k_{p}$ is determined with a considerable measurement uncertainty that is made by both statistical uncertainty, while determining the initial rate, 
and systematic uncertainty as a result of quasi-steady approximation applied. The former can be calculated precisely as the experimental data approximation takes place, the average relative uncertainty being $15 \%$, that can correlate with the average statistical uncertainty while determining $k_{p}$ according to the experimental data obtained by various researchers, i.e., $8 \%$ (Table 1 ).

The latter was determined as follows by differentiating the expressions (4-5):

$$
\frac{\Delta k_{p}}{k_{p}}=\frac{\Delta V}{V}+\frac{\Delta\left[R^{\bullet}\right]}{\left[R^{\bullet}\right]}+\frac{\Delta[M]_{0}}{[M]_{0}}, \frac{\Delta\left[R^{\bullet}\right]}{\left[R^{\bullet}\right]}=\frac{1}{2}\left(\frac{\Delta[I]_{0}}{[I]_{0}}+\frac{\Delta k_{t_{0}}}{k_{t_{0}}}\right),
$$

where $\Delta V / V$ is statistical uncertainty. Thus, monomer and initiator systematic uncertainty can be determined. In case the formulas (4-5) are used, then monomer concentration is thought to be intact. In fact, within the section $0-20 \%$ of the curve the concentration drops by $20 \%$. The medial value $\Delta[M]_{0} /[M]_{0}=10 \%$ was considered to be the uncertainty. Likewise, the initiator concentration is varied within the section to the value of $\Delta[I]_{0} /\left[I_{0}=10 \%\right.$. (AIBN, $\left.60^{\circ} \mathrm{C}\right)$. In case these uncertainties fail to be taken into account, then the macroradicals concentration increases and there is a decrease in the value of the chain growth reaction rate.

The uncertainty, being the result of reducing the PMMA chain termination rate was determined using the Hui-Hamielec model [8]. According to the expression (5) the chain termination rate within the section $0-20 \%$ is reduced by $71 \%\left(60^{\circ} \mathrm{C}\right)$. This type of uncertainty results in $k_{p}$ increase in quasi-steady approximation and partially compensates the uncertainties in the monomer and initiator concentrations.

Thus, it can be assumed that the systematic uncertainty, in case quasi-steady approximation is applied for the purposes of MMA polymerization, results in increasing $k_{p}$ by $50 \%$.

Having approximated the average values of chain growth reaction rates (Table 3) using the Arrhenius equation form, we obtained the fol- 
lowing $k_{p}$ value: $k_{p}=7.26 \cdot 10^{5} \cdot \exp (-2333 / T)$. The value correlates with the ones published earlier that were determined using the SIP method [10-11] (Pic. 2).

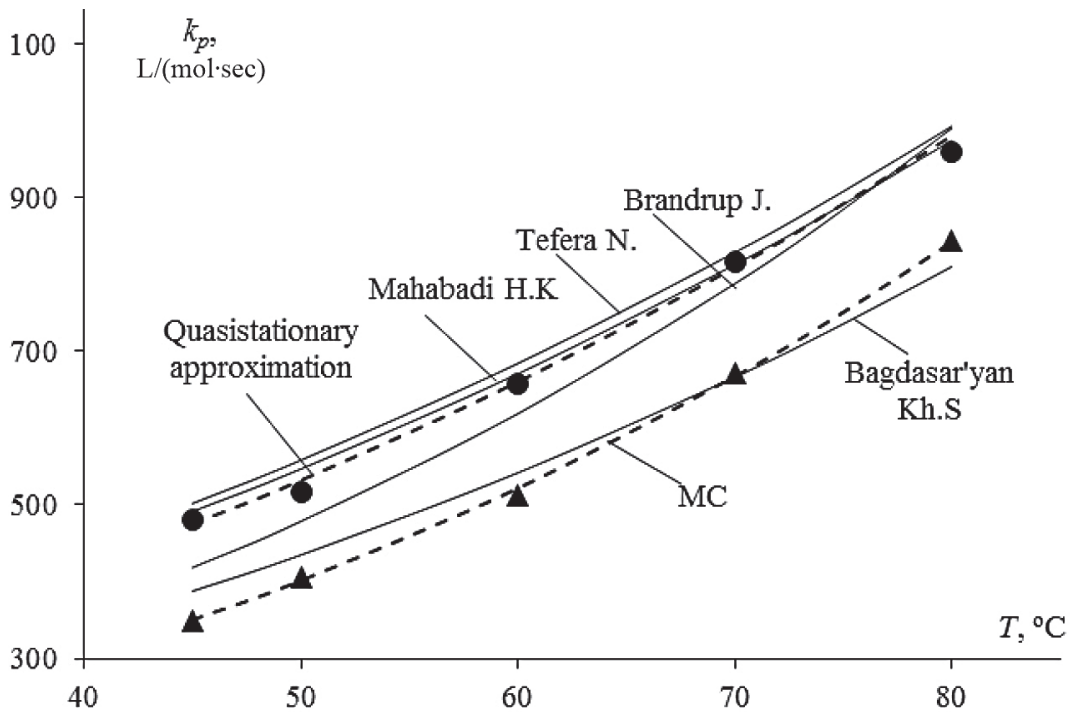

Pic. 2. Temperature dependence of chain growth reaction rate by MMA polymerization

The chain growth reaction rates determined using the SIP method [10-11] were found on the initial polymerization section that proves the correct nature of the chain growth reaction rate value in quasi-steady approximation.

\section{MMA polymerization simulation using the MC method Algorithm description}

The MC method is thought to be an efficient for solving complex systems of equations. The classic algorithm of the MC method is to select events for each element of the assembly, using a pseudorandom number generator. However, there are cases when nothing happens to the selected element, and as time spent on the calculation depends 
on the number of the sensor's hit count, then the use of this approach considerably increases the amount of time spent on the calculation.

The proposed simulation algorithm, that uses the MC method, rules out non-productive hits that, in turn, increases the algorithm's efficiency.

It was assumed that at the initial time $(t=0)$ the size of the assembly is equal to the initial number of initiator molecules. The entire polymerization process is divided into small time intervals $(d t)$. The idea of the algorithm is that at each time step an assembly element number is randomly selected for the event. And for each element the event occurs with probability equal to unity. The number of random selections of acts at a step corresponds to the reaction rates. This simulation approach enables either to reduce the computer calculation time to a great extent or increase the statistical assembly [30,31].

A single act of chain growth reaction occurs by increasing the number of main-chain links per unit. The number of monomer molecules is reduced by unity.

An act of chain transfer to monomer was simulated as follows. The assembly element number (macroradical) was selected, the one that contains a growing chain undergoing chain transfer reaction to monomer. At the time of the transfer, a 'dead' macromolecule is formed, its polymerization degree at the time of transfer being equal to the length of the growing molecule. At the time of the transfer, a new growing chain is formed, its length being equal to unity.

An act of chain termination is performed by one of two possible mechanisms: disproportioning or recombination. The number of two macroradicals was selected randomly at the time of one of the two possible chain termination reactions. When the macroradicals disproportioning takes place, two 'dead' macromolecules are formed with the correspondent chain lengths. When the recombination reaction takes place, one 'dead' macromolecule is formed with the chain length equal to the sum of the chain lengths of the collided radicals. The 
number of macroradicals as a result of the chain termination act was reduced by two unities.

When the simulation process took place, the number of 'dead' macromolecules with a specific chain length was counted, the ones being formed during the acts of chain transfer to monomer and chain termination; which allowed to determine the number-average and mass-average MM PMMA as well as molecular-mass distribution (MMD) at different polymerization periods.

The program was implemented in the Borland Delphi 7 software development kit, the calculations were made on the AMD Athlon PC (2.81 GHz, $2 \mathrm{~GB})$. The run time is directly proportional to the size of the assembly, whereas it is the assembly size of 50-100 million initiator molecules that is thought to be quite sufficient for correct MMD simulation. For example, if the assembly is comprised by $10^{8}$ initiator molecules, which corresponds to the assembly of $10^{12}$ monomer molecules, then a 1-hour simulation of MMA polymerization totalled 25 minutes, which is significantly faster than in [4], in which the above-mentioned process took 2 hours run time (on a much more powerful IntelCore i5 ( 2 cores, $3.46 \mathrm{GHz}, 16 \mathrm{~GB}$ ) computer) while the assembly was characterized as containing $10^{11}$ monomer molecules. Thus, the calculating program, being the result of the study, is believed to be over 50 times as efficient.

\section{The Hui-Hamielec model parameter determination}

The values of the coefficients $A_{1}, A_{2}, A_{3}$ for the mass radical polymerization of styrene can be found in [8]. An indispensable condition for this process is thought to be the monotonic decrease in the chain termination rate as the conversion increases. The values of the HuiHamielec model parameters for MMA radical polymerization were determined in [32] by solving the inverse problem, along with varying the Hui-Hamielec coefficients and chain growth reaction rate. The task was to achieve matching of experimental and calculated dependences 
of the MMA conversions in the presence of AIBN initiator within a temperature range of $50-80^{\circ} \mathrm{C}$ at different initial concentrations of the initiator. It was found that the inverse problem has several solutions (sets) that describe the experimental conversions being characterized by virtually the same correlation coefficient. Firstly, some sets belonging to high conversions area lead to the increase in $k_{t}$. These sets were ruled out from the solution as having no physical meaning. Secondly, it was found that the $k_{t}(x)$ dependence has an intersection point at different temperatures (Pic. 3b). Therefore, the sets, their intersection point being found in the conversion domain $x<1$, were also excluded. As a result, the following solution was determined:

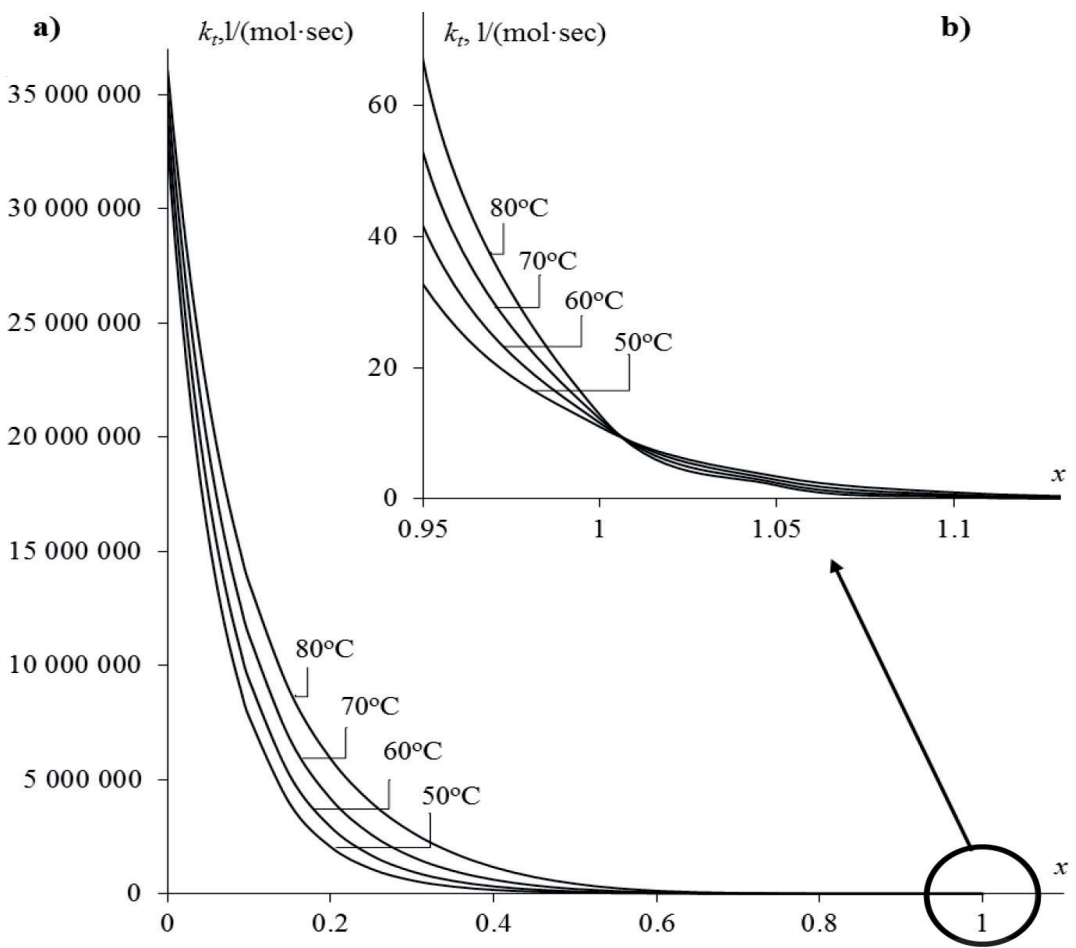

Pic. 3. Chain termination rate dependence on conversion at different temperatures of MMA polymerization 
The Hui-Hamielec model coefficients (8) were applied to take the gel effects into account while simulating the MMA mass radical polymerization by the MC method.

\section{Program testing}

In order to test the simulation program for the MMA mass radical polymerization by the $\mathrm{MC}$ method computational experiments were carried out for certain extreme cases.

Having performed the intact macromolecules growth simulation with no transfer or chain termination reactions, the expected MMD was obtained that can be described by the Poisson distribution function (Pic. 4):

$$
q_{w}(p)=\frac{p}{\bar{P}_{n}} \frac{\left(\bar{P}_{n}\right)^{p}}{p !} \exp \left(-\bar{P}_{n}\right)
$$

where $p$ is polymerization degree, $\bar{P}_{n}$ is number-average polymerization degree.

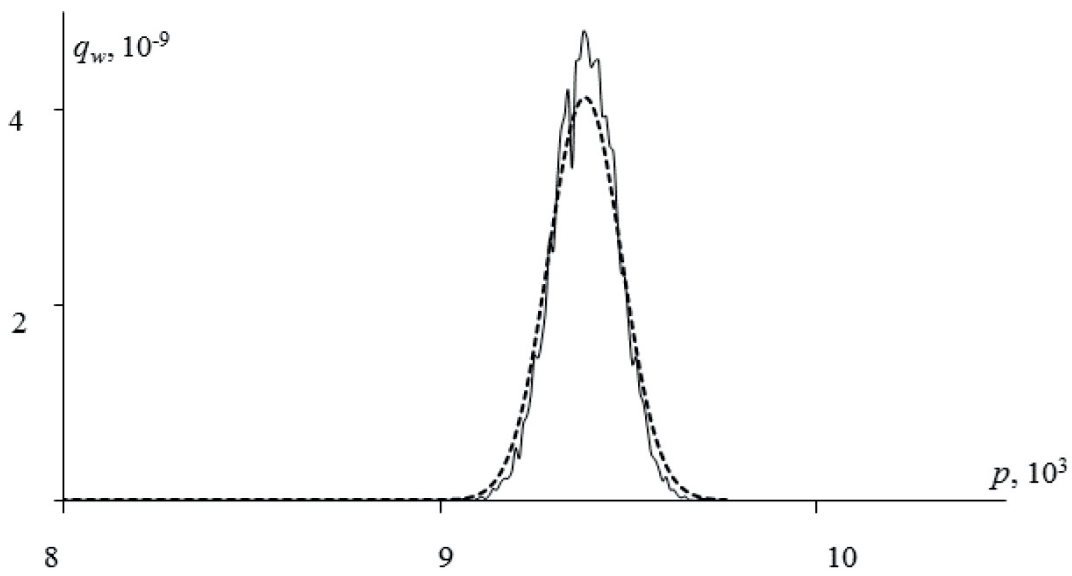

Pic. 4. MMP, obtained as a result of the chain growth reaction rate simulation: dashed line is used to denote the Poisson distribution (9), while solid line denote what was obtained by the MC simulation at $t=10 \mathrm{c}, k_{p}=100 \mathrm{~L} /(\mathrm{mol} \cdot \mathrm{sec})$, the assembly size being $100 \mathrm{mln} ., T=70^{\circ} \mathrm{C},[\mathrm{AIBN}]_{0}=1 \mathrm{mmol} / \mathrm{L}$ 
It is known, that the chain growth, growing chain transfer and/or radical disproportioning reaction should result in MMD formation being correspondent to the Flory distribution function:

$$
q_{w}(p)=\frac{p}{\bar{P}_{n}^{2}} \exp \left(-\frac{p}{\bar{P}_{n}}\right)
$$

It is but true, that the type of MMD obtained as a result of chain growth reaction rate and chain transfer to monomer simulation is the Flory distribution (Pic. 5, curve 1), whereas the chain growth reaction rate, chain transfer to monomer and radical disproportioning simulation leads to the same result (Pic. 5, curve 2).

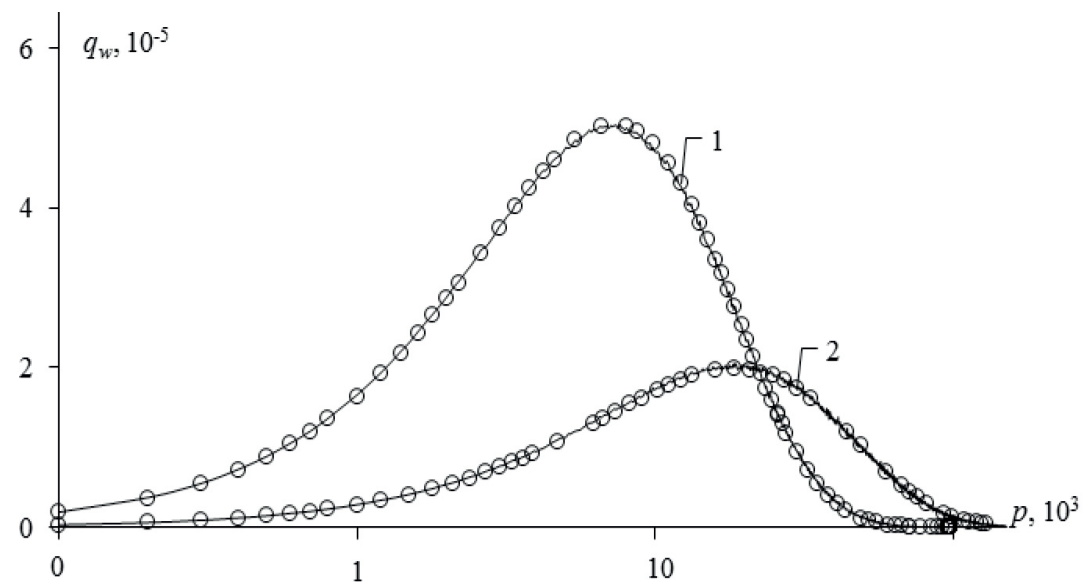

Pic. 5. PMMA MMD: $\odot-$ the Flory distribution (10), solid lines $-\mathrm{MC}$

(the assembly size $-50 \mathrm{mln} ., T=70^{\circ} \mathrm{C},[\mathrm{PBO}]_{0}=1 \mathrm{mmol} / \mathrm{L}, k_{p}=670 \mathrm{~L} /(\mathrm{mol} \cdot \mathrm{sec}$ ), $\left.k_{m}=0.035 \mathrm{~L} /(\mathrm{mol} \cdot \mathrm{sec})\right), 1-$ chain growth reaction rate and chain transfer to monomer simulation $(t=190 \mathrm{c}) ; 2$ - chain growth reaction rate, chain transfer to monomer and radical disproportioning simulation $\left(t=6600 \mathrm{c}, k_{\text {disp }}\right.$ (Table 2))

In case only chain growth and radical recombination reactions are observed or radical recombination prevails over chain transfer to monomer, then, as a result, the type of MMD should be formed, the one described by the Schulz distribution: 


$$
q_{w}(p)=\left(\frac{2}{\bar{P}_{n}}\right)^{2} \frac{p^{2}}{\bar{P}_{n}} \exp \left(-\frac{2 p}{\bar{P}_{n}}\right)
$$

In this asymptotic case, the program testing was also proved successful (Pic. 6).

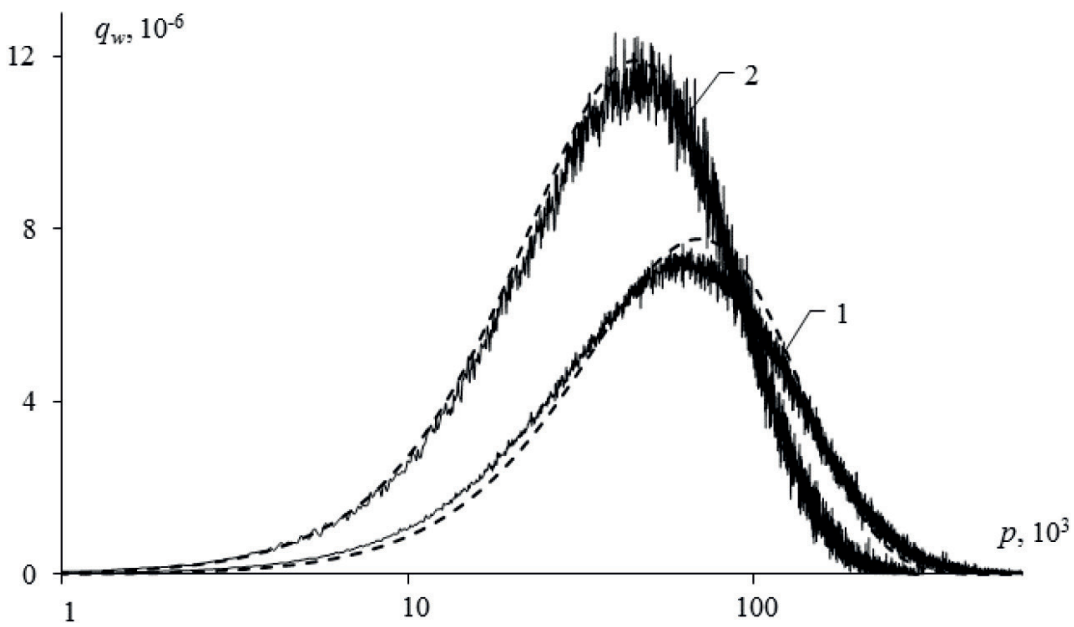

Pic. 6. PMMA MMD, dashed lines - the Schulz distribution (11), solid lines $-\mathrm{MC}$ (the assembly size $-50 \mathrm{mln}$., $T=70^{\circ} \mathrm{C},[\mathrm{PBO}]_{0}=1 \mathrm{mmol} / \mathrm{L}$, $k_{p}=670 \mathrm{~L} /(\mathrm{mol} \cdot \mathrm{sec}), t=1 \mathrm{4}, k_{\text {com }}$ (Table 2)): 1 - chain growth reaction rate and radical recombination; 2 - chain growth reaction rate and chain transfer to monomer simulation $\left(k_{m}=10^{-4} \mathrm{~J} /(\mathrm{mol} \cdot \mathrm{sec})\right)$ and radical recombination

To test the MC results, the system of differential equations (1-3) was solved using the RK4 method for the case of MMA polymerization along with the presence of $\mathrm{PBO}$ having initial concentration of 1 $\mathrm{mmol} / \mathrm{L}$ at $T=60^{\circ} \mathrm{C}$. The results of the system solution, that was carried out using both the methods, correlated to a full extent (Pic. 7).

Thus, the test results show that the program that was developed to simulate substance initiated radical polymerization by the MC method taking the gel effect into account according to the Hui-Hamielec model is capable of correct reproduction of both monomer conversion variation and MMD while polymerization is in progress. 


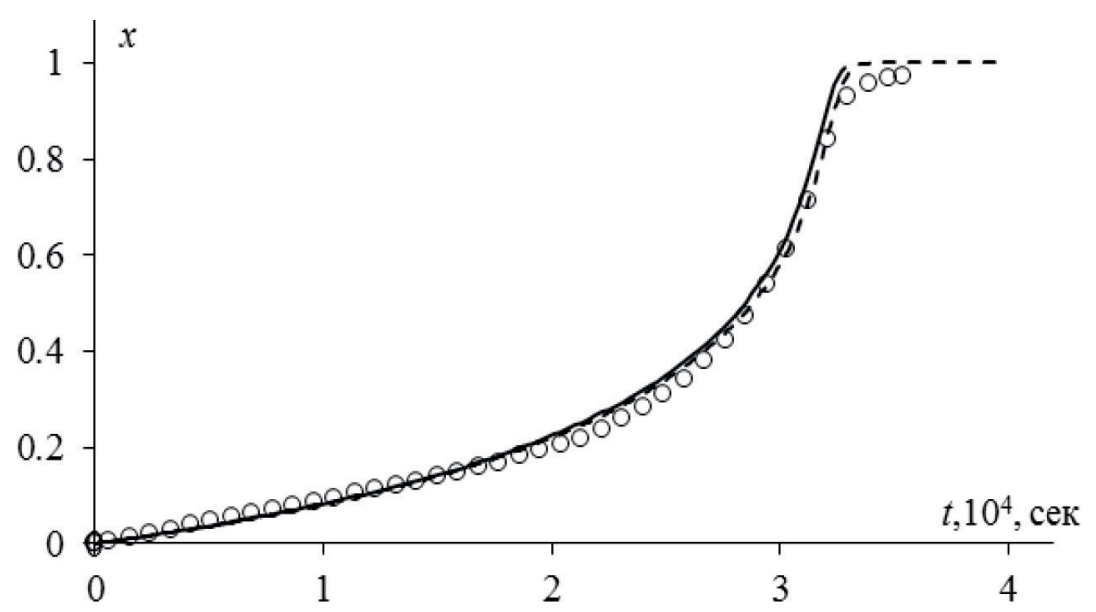

Pic. 7. MMA conversion dependency: solid line - MC method, dashed line - RK4, $\circ-$ experimental data $\left([\mathrm{PBO}]_{0}=1 \mathrm{mmol} / \mathrm{L}, 60^{\circ} \mathrm{C}\right)$

\section{Conversion dependencies}

The strategy of determining the chain growth reaction rate was to solve the inverse problem by approximating the MMA experimental conversion dependencies in the presence of AIBN initiator at its different initial concentrations. That is, one needs to minimize the functional:

$$
F\left(k_{p}\right)=\sum_{i=1}^{i_{\max }}\left(x_{i}^{\text {exper }}-x_{i}^{\text {calc }}\right)^{2} \text {, where } i \text { is the number of the actual data }
$$

point being relative to the $i_{\max }$ value selection. The MMA experimental conversion dependencies never achieve theoretically maximum possible value of $x=1$, but only tend to reach a certain limit value of $x_{\text {limit }}<1$ (Pic. 8). This is explained by PMMA glass transition in the high conversions area [11,33-34], in which all of the reactions change to a diffusion mode (I). The theoretical description of the glass transition within the MMA polymerization process is thought to be possible provided the additional kinetic parameters are introduced into the model [34-35], which complicates the model. Therefore, we have limited the $i_{\max }$ to exclude the glass transition area. 


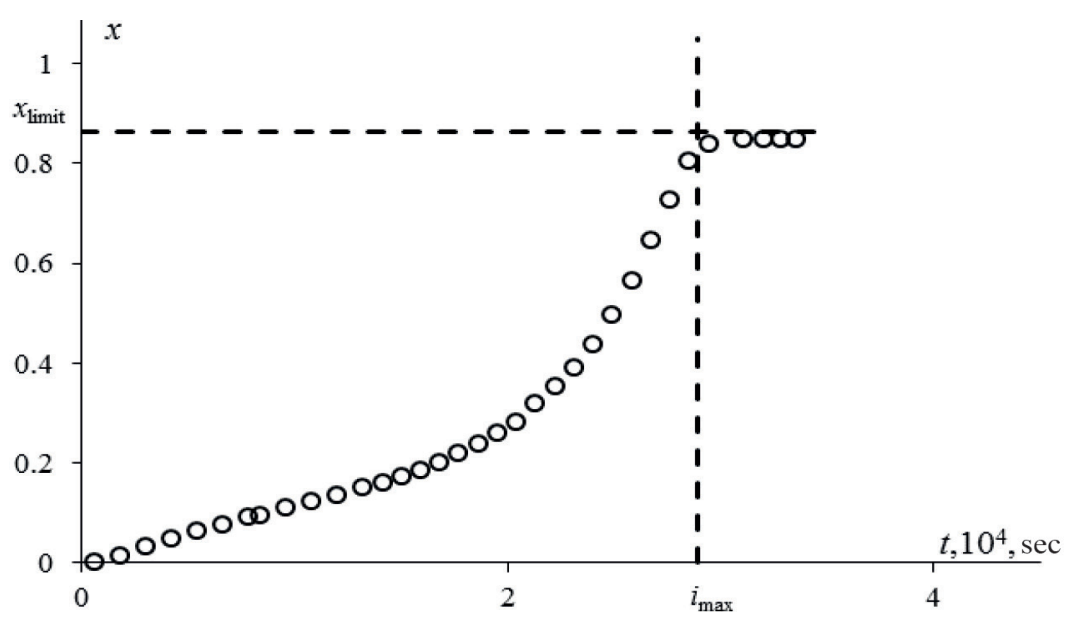

Pic. 8. MMA experimental conversion dependency on polymerization time $\left([\mathrm{AIBN}]_{0}=1 \mathrm{mmol} / \mathrm{L}, \mathrm{T}=60^{\circ} \mathrm{C}\right)$

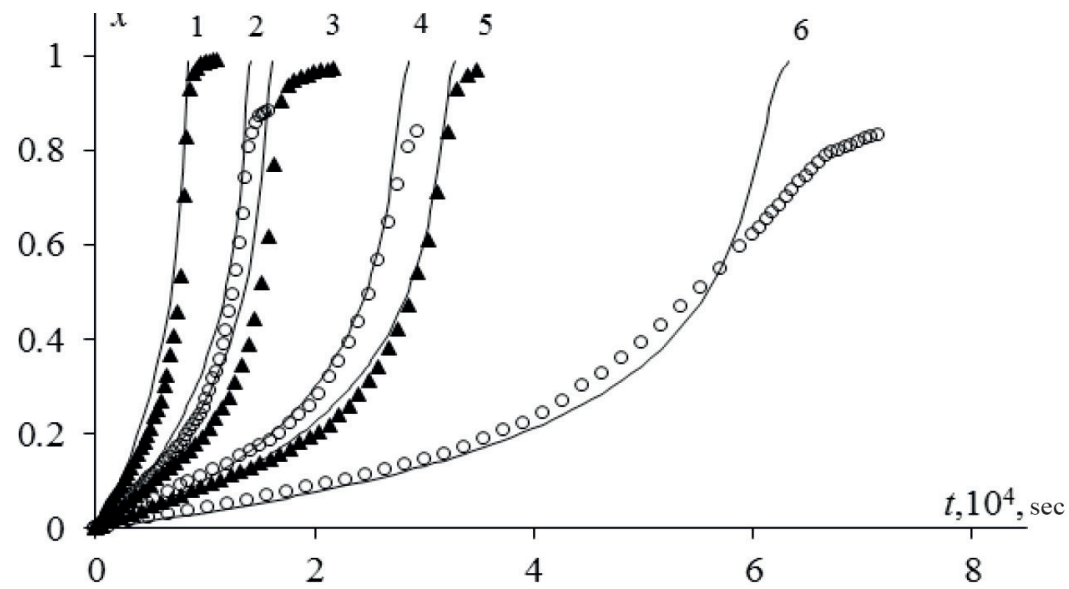

Pic. 9. MMA conversion polymerization: $\odot-[\mathrm{AIBN}]_{0}=1 \mathrm{mmol} / \mathrm{L}$, $\Delta-[\mathrm{PBO}]_{0}=1 \mathrm{mmol} / \mathrm{L} ; 1-80^{\circ} \mathrm{C} ; 2,3-70^{\circ} \mathrm{C} ; 5,4-60^{\circ} \mathrm{C} ; 6-50^{\circ} \mathrm{C}$; symbols experimental data, lines - obtained by the $\mathrm{MC}$ simulation

The chain growth reaction rate was determined using the experimental data corpus on MMA radical polymerization in the presence of AIBN initiator, then it was tested using the PBO initiator. The convinc- 
ing correlation of estimated and experimentally observed conversion curves (Pic. 9). The parameter $k_{p}=2.5 \cdot 10^{6} \cdot \exp (-2823 / T), \mathrm{L} /(\mathrm{mol} \cdot \mathrm{sec})$ (Pic. 2) corresponds to the $k_{p}$ value range [12] (Table 1).

\section{Macroradicals concentration}

Only one [29] work contains data on experimentally measured macroradicals concentration within the MMA polymerization process carried out at $60^{\circ} \mathrm{C}$ in the presence of AIBN with the initial concentration of 100 $\mathrm{mmol} / \mathrm{L}$. The work also contains the dependence $y(t)=\left[R^{*}\right] / M$, which in the coordinates $\left[R^{\circ}\right](t)$ is almost identical to the radicals concentration within the MC simulation (Pic. 10,1-2), which again confirms adequacy of the Hui-Hamielec model in case of the MMA polymerization.

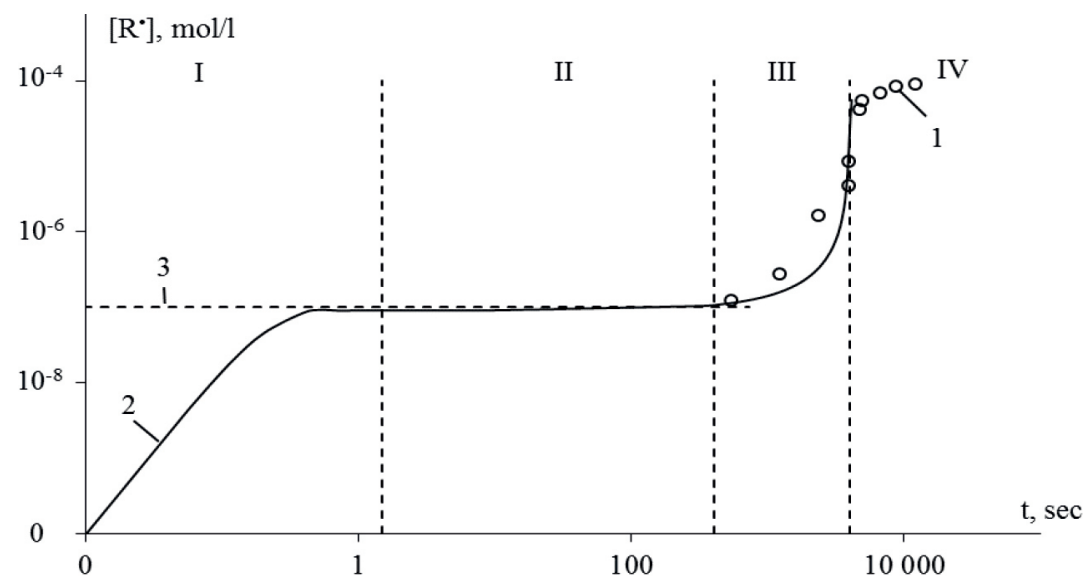

Pic. 10. Macroradicals concentration dependency on the MMA polymerization: 1 - experiment [2], 2 - the $\mathrm{MC}$ simulation $\left(60^{\circ} \mathrm{C},[\mathrm{AIBN}]_{0}=100 \mathrm{mmol} / \mathrm{L}, k_{p}=520\right.$

$\mathrm{L} /(\mathrm{mol} \cdot \mathrm{sec})$ likewise $), 3$ - quasi-steady approximation $\left(k_{p}=660 \mathrm{~L} /(\mathrm{mol} \cdot \mathrm{sec})\right)$

There are four main sections in the kinetic curve: I - the initial section of the concentration increase up to the steady-state value, II - the section with a constant concentration of macroradicals, III - the section on which there is a sharp increase in the macroradicals concentration, IV the glass transition section. Note that the length of the first two sections 
is quite small compared to the polymerization time section. Almost all of the monomer gets polymerized within sector III, whereas on section IV all polymer reactions slow down because of all the glass transition.

\section{PMMA MMD}

Thus, the chain growth reaction rate was determined on the first stage of the inverse problem solution On the second stage the transfer to monomer reaction rate was determined using the correlation of estimated and experimentally observed values (at $50-70^{\circ} \mathrm{C}$ ) of average molecular masses and MMD (Pic. 11). Having approximated the $k_{m}$ value, $k_{m}=2.79 \cdot 10^{5} \cdot \exp (-5450 / T), \mathrm{L} /(\mathrm{mol} \cdot \mathrm{sec})$ was determined.

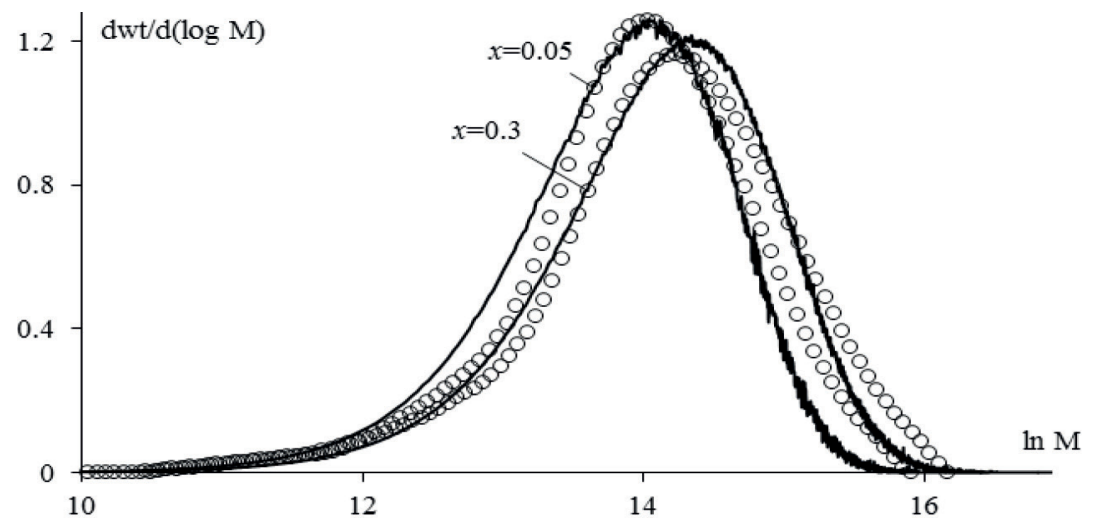

Pic. 11. Typical PMMA MMD: symbols - experimental values $\left(T=70^{\circ} \mathrm{C}\right.$, $\left.[\mathrm{PBO}]_{0}=1 \mathrm{mmol} / \mathrm{L}\right)$, solid line - what was obtained by the $\mathrm{MC}$ simulation at $k_{p}=670 \mathrm{~L} /(\mathrm{mol} \cdot \mathrm{sec}), k_{m}=0.035 \mathrm{~L} /(\mathrm{mol} \cdot \mathrm{sec})$

Thus, it is the algorithm of the substance initiated MMA mass radical polymerization taking the gel effect into account according to the Hui-Hamielec model that was developed [8] as well as the model parameters were determined.

\section{Conclusion}

The chain growth reaction rate in quasi-steady approximation as well as by the MC method was determined for the purposes of MMA 
mass radical polymerization in the presence of both AIBN and PBO within the temperature range of $50-90^{\circ} \mathrm{C}$. The use of quasi-steady approximation results in significant increase of the rate. Due to this, the gel effect should be taken into account, that was performed while simulating the MC. The chain growth reaction rate value, obtained as a result of the simulation process, is thought to be more correct.

The pertinent theoretical model of the substance initiated MMA mass radical polymerization taking the gel effect into account according to the Hui-Hamielec model was developed.

The original algorithm was created to simulate radical polymerization using the MC method as well as the software was developed that enables to spend adequate run time to calculate reagent concentration at various polymerization periods, speed of the simulated reactions, polymer MMD and average MM values. One of the most significant advantages of the developed algorithm of radical polymerization simulation is thought to be the fact that it can be easily modified by adding new block to the program thus making it possible to simulate other reactions.

\section{References}

1. Bain E.D., Turgman-Cohen S., Genzer J. Progress in computer simulation of bulk, confined, and surface-initiated polymerizations. Macromol. Theory Simul., 2013, v. 22, pp. 8-30.

2. Yanborisov V.M., Yanborisov E.V., Spivak S.I. Algorithm of Modeling Ziegler-Natta Polymerization taking account of change of Catalyst Activity. Mathem. mod., 2010, v. 22, №3, pp. 15-25.

3. Yanborisov VM., Yanborisov E.V., Spivak S.I., Ziganshina A.S., Ulitin N.V. The evolution of the molecular weight distribution of polydienes during polymerization on polycenter catalysts of the Ziegler-Natta. Herald of Kazan State Technological University, 2014, v.17, №4, pp. 155-158.

4. Drache M., Drache G. Simulating controlled radical polymerizations with mcPolymer - A Monte Carlo approach. Polymers, 2012, v. 4, pp. 1416-1442. 
5. Trommsdorff E., Kohle H., Lagally P. Zur Polymerisation des Methacrylsiiuremethylesters. J. Macromol. Chem. and Physics, 1948, v. 1, № 3, pp. 169-196.

6. Gladyshev G.P., Popov V.A. Radical polymerization at high degrees of conversion. Nauka (Science, in Rus.), Moscow, 1974. P. 244.

7. Brooks B.W. Viscosity Effects in the Free-Radical Polymerization of Methyl Methacrylate. Proc. R. Soc. Lond., 1977, v. 357, № A, pp. 183-192.

8. Hui A.W., Hamielec A.E. Thermal polymerization of styrene at high conversions and temperatures. An experimental study. J. Appl. Polym. Sci., 1972, v. 16, pp. 749-469.

9. Bagdasar'yan Kh.S. Theory of free-radical polymerization. Jerusalem: Israel Program for Scientific Translations, Hartford, Conn., D. Davey, 1968. P. 328.

10. Mahabadi H.K., O’Driscoll K.F. Absolute rate constants in free-radical polymerization. J. Macromol. Sci. Chem., 1977, v. 11 № A, № 5, pp. 967-976.

11. Tefera N., Weickert G., Westerterp K. R. Modeling of free radical polymerization up to high conversion: 2. Development of a mathematical model. J. Appl. Polym. Sci., 1997, v. 63, № 12, pp. 1663-1680.

12. Brandrup J., Immergut E. H., Grulke E. A. Polymer handbook, fourth edition. John Wiley \&Sons. Inc., 1999. P. 2366.

13. Nagy A., Foldes-Berezsnich T., Tudos F. Kinetics of Radical Polymerization-XLIII investigation of the polymerization of Methyl Acrylate in solution by the rotating sector method. J. Eur. Polym., 1984, v. 20, № 1 , pp. 25-29.

14. Mahabadi H.K., O’Driscoll K.F. Spatially Intermittent Polymerization. J. of Polym. Sci., 1976, v. 14, pp. 869-881.

15. Chiu W.Y, Carratt G.M., Soong D.S. A Computer model for the Gel Effect in free-radical polymerization. Macromolecules, 1983, v. 16, pp. 348-357.

16. Kiparissides C., Achilias D. Modeling of diffusion-controlled free-radical polymerization reactions. J. Appl. Polym. Sci., 1988, v. 35, pp. 1303-1323.

17. Emanuel N.M., Kuzimina M.G. Experimental methods of chemical kinetics/ University of Moscow, Moscow, 1985. P. 384. 
18. Willemse R.X.E. New Insights into Free-Radical (Co)Polymerization Kinetics. Technische Universiteit Eindhoven, Eindhoven, 2005. P. 160.

19. Hutchinson R.A., Aronson M.T., Richards J.R. Analysis of Pulsed-Laser-Generated Molecular Weight Distributions for the Determination of Propagation Rate Coefficients. J. Macromol., 1993, v. 26, pp. 6410-6415. 20. Fenouillot F., Terrisse J., Rimlinger T. Polymerization of methyl methacrylate at high temperature with 1-butanethiol as chain transfer agent. J. Appl. Polym. Sci., 1999, v. 72, №12, pp. 1589-1599.

21. Bamford C.H., Barb W.G., Jenkins A.D., Onyon. P.F. The kinetics of vinyl polymerization by radical mechanisms. Butterworths scientific publication, 1958, pp. 103-117.

22. Tobolsky A.V., Baysal B. A Review of Rates of Initiation in Vinyl Polymerization: Styrene and Methyl Methacrylate. Polym. Sci., 1953, v. 11, № 5, pp. 471-486.

23. Gladyshev G.P., Gibov K.M. Polymerization at high degrees of conversion and methods of research. Alma-Ata: Nauka (Science, in Rus.), 1968. P. 142.

24. Ito K. Estimation of Molecular Weight in Terms of the Gel Effect in Radical Polymerization. J. Polymer, 1980, v. 12, pp. 499-506.

25. Marten, F.L., Hamielec A.E., High conversion diffusion-controlled polymerization. ACS Symp. Ser., 1979, v. 104, pp. 43-70.

26. Balke S.T., Hamielec A. E. Bulk Polymerization of Methyl Methacrylate. J. Appl. Polym. Sci., 1973, v. 17, pp. 905-949.

27. O’Neil G.A., Wisnudel M.B., Torkelson J.M. An Evaluation of Free Volume Approaches to Describe the Gel Effect in Free Radical Polymerization. Macromol., 1998, v.31, №3, pp. 4537-4545.

28. Stickler M., Panke D. Polymerization of Methyl Methacrylate up to High Degrees of Conversion: Experimental Investigation of the Diffusion-Controlled Polymerization. J. Polym. Sci., 1984, v. 22, pp. 2243-2253.

29. Carswell T.G., Hill D.J.T., Londero D.I., O’Donnell J.H., Pomery P.J., Winzor C.L. Kinetic parameters for polymerization of methyl methacrylate at $60^{\circ}$ C. Polymer., 1992, v. 33, № 1, pp. 137-140. 
30. Yanborisov V.M., Sultanova A.A., Kolesov S.V. Sistemy upravleniya $i$ informatsionnye tekhnologii, 2015, V. 62, №4, pp. 24-30.

31. Yanborisov V.M., Sultanova A.A., Kolesov S.V. Informatsionnye tekhnologii modelirovaniya i upravleniya, 2015, V. 95, №5, pp. 418-428.

32. Kolesov S.V., Shiyan D.A., Yanborisov V.M., Burakova A.O., Tereshchenco K.A., Ulitin N.V., Zaikov G.E. Description of Radical Polymerization kinetics of methyl methacrylate with consideration of Autoacceleration. Journal of Characterization and Development of Novel Materials, 2015, V. 7, pp. 1-9.

33. Vrentas J.S. Review of the applications of free volume theory for diffusion in polymers. Polym. Rev., 1981, v. 15, pp. 136-138.

34. Fleury P.-A., Meyer Th., Renken A. Solution polymerization of methyl-methacrylate at high conversion in a recycle tubular reactor. Chemical Engineering Science, 1992, v. 47, №. 9, pp. 2597-2602.

35. Nising P., Meyer T. Mathematical-modeling of polymerization kinetics at high monomer conversions a critical-review. Plaste Kautsch., 1986, v. 33, №8, pp. 281-285.

\section{DATA ABOUT THE AUTHORS}

Sultanova A.A.

Ufa State Oil Technical University

145, Chernyshevskiy Str., Ufa, 450078, Russian Federation tyc92@yandex.ru

\section{Yanborisov V.M.}

Ufa State Oil Technical University

145, Chernyshevskiy Str., Ufa, 450078, Russian Federation yanborisovvm@mail.ru

\section{Kolesov S.V.}

Ufa Institute of Chemistry of the Russian Academy of Sciences 1, Kosmonavtov Str., Ufa, 450062, Russian Federation kolesovservic@rambler.ru 